\title{
Smart Feeder/Shuttle Bus Service: Consumer Research and Design
}

\author{
Y. B. Yim, University of California at Berkeley \\ Avishai (Avi) Ceder, Technion-Israel Institute of Technology
}

\begin{abstract}
While long-haul express transit is gaining ridership, consumers are increasingly experiencing limited access to express transit due to saturated parking at and around stations. The smart shuttle concept was introduced to provide easy access to express transit. Smart shuttles will be equipped with advanced public transit system technologies to track shuttle vehicle locations and disseminate up-to-the-minute shuttle arrival information to consumers. The first step toward deployment of the smart shuttle service was a market study of short-haul feeders. This article presents the results of a telephone survey of randomly-generated Castro Valley households. Castro Valley is a suburban community in the San Francisco Bay Area, and many residents commute by BART (Bay Area Rapid Transit). The survey suggested that three fifths of the survey participants were likely to take the shuttle to the BART station. The interest in using the smart shuttle service is strongly associated with gender, auto ownership, ethnicity, and employment status. Females were more interested in taking a shuttle than males. Employed people were more likely to use BART because of the shuttle. Households without a car or with fewer cars were more interested in taking a shuttle. The cost, travel time, and reliability of the service are the most important attributes in the design of a shuttle. The subsequent phase of this research will be a field test of the smart shuttle with optimal routing solutions. The value of the research is the evaluation of the field test, which will assess the improvement of BART access and the cost-effectiveness of the short-haul feeder operation. Ideally, this smart feeder/
\end{abstract}


shuttle system will provide advanced and attractive service that operates reliably and relatively rapidly and acts as part of the passenger door-to-door chain with smooth and synchronized transfers. In order to approach the design of this innovative feeder/shuttle system, new integration and routing concepts are presented based on the consumer research.

\section{Introduction}

A growing concern for public transportation is its inability to encourage people to switch their mode of transportation from solo driving to shared driving. As cities expand, transit ridership decreases while auto ownership increases. Although overall transit ridership is declining in cities, an encouraging trend is increased ridership in long-haul express bus or rail transit. When long-haul express transit systems were built in the 1970s and 1980s in California, parking facilities were also provided for riders to park their cars and ride a train. The concept of "park and ride" was readily accepted by the public, and a large number of commuters preferred to take an express bus or train to avoid rush-hour traffic and prohibitive parking costs. As regional economies grew and more jobs became available, commuters increasingly relied on the express transit service (e.g., in the San Francisco Bay Area). In 1999, the Bay Area Rapid Transit (BART) carried 285,000 commuters each weekday, compared to 255,000 in 1992 (11.7\% growth over seven years). Automobiles continued to be the major access mode to BART. Approximately 80 percent of the park-and-ride BART customers parked in the BART parking lot while the remaining 20 percent were parked off-site around the BART station on residential streets. As the BART parking lots became full as early as 7:00 A.M., the overflow vehicles took up space on residential streets, inviting an increasing number of neighborhood complaints around the BART stations.

Some BART riders claimed that they have had to switch back to driving because of the severe access problems with BART. All 39 BART stations have access problems. Although local buses are able to serve BART stations at certain times, they do not necessarily meet the needs of BART customers' schedules. Local bus and BART schedules are not well synchronized and, thus, transfer times are often unnecessarily long. Long waits are one of the major reasons people do not want to travel by public transit.

A smart shuttle/bus is an alternative travel method to personal vehicle or bus transit for short-haul feeders. The smart shuttle concept has the potential for 
improvement of transportation accessibility for those who may not want to drive or take a bus to express transit stations. Features of the smart shuttle will include both fixed- and flexible-demand responsive systems based on the time and location of the service, use of Advanced Public Transit Systems (APTS) technologies for timely dissemination of the shuttle arrival time, and economical operation of the smart shuttle system. Smart shuttle vehicles will be tracked via automated vehicle identification (AVI) system and Global Positioning System (GPS). Ideally, smart shuttles would provide attractive feeder and distributor services with advanced transportation technologies contributing to transit operations that are reliable, productive, and efficient. Smart shuttles could possibly provide door-todoor service with smooth and seamless operation and synchronized scheduling between long- and short-haul transit operations.

The short-haul feeder study as a whole has four broad objectives:

1. latent demand study (or market study) of short-haul feeders,

2. design of innovative routing strategies,

3. deployment of a smart shuttle for a field test, and

4. evaluation of the smart shuttle system.

The latent demand study is being performed using the survey research method. The routing strategy study was done with simulation. The field test and evaluation will be done following the first two studies.

This article presents the findings of the latent demand study, which is concerned with consumer response to a smart shuttle system for short-haul feeders. The article provides an understanding of the user side of short-haul feeder service. The study investigated service attributes that would attract consumers. The decision to take transit will depend on trade-offs between personalized transit and the personal vehicle. If the goal of a demand responsive transit service is to capture the driver population, a personalized transit service needs to be as convenient as a personal vehicle. If the goal is to improve the transit service for those who are captive transit users, personalized transit needs to be better than fixed-route service.

The central issue is what attributes of personalized transit will attract consumers and what segment of the population will use it. The target population of potential users could include commuters, the elderly, persons with disabilities, and children. 
The present study investigated desired attributes that will attract consumers. Key research questions were:

1. What kind of service features will likely attract consumers enough for them to switch from their single-occupancy vehicle (SOV) to a smart shuttle?

2. Who will use it and why?

The objectives of the latent demand study are:

- to assess the travel characteristics and profiles of potential users of the smart shuttle with respect to socioeconomic variables, and

- to identify attributes necessary to support the smart shuttle system, including acceptable waiting time, number of stops, size of shuttle vehicles, travel time, and fare structure.

The findings of the demand study were considered in the design of the Castro Valley' smart shuttle system to improve BART station accessibility with new integration and routing concepts.

Castro Valley, a community within the incorporated County of Alameda in California was selected for a field test. The reasons for selecting Castro Valley were:

- The community is one of the fastest growing suburban communities in northern California.

- BART and Alameda Contra Costa Transit (AC Transit) serve Castro Valley.

- The community experiences severe access problems to the Castro Valley BART station.

- Castro Valley has a severe shortage of parking around the BART and AC express transit stations.

- There is a growing concern with overflow parking on neighborhood streets.

While the innovative routing strategies are explained in this work, the simulation study for these strategies for the Castro Valley community is presented by Ceder and Yim (2002).

\section{Background}

An important issue regarding a smart shuttle is its design based on a good understanding of user needs and desires and how new technologies can enhance the 
smart shuttle service. In the past, dial-a-ride or door-to-door paratransit played a vital role in North American transit planning in providing equitable transportation services to elderly and handicapped persons. But these concepts do not offer transit services accessible to the entire population that needs mobility (Borndorfer et al.1999; loachim et al.1995). Two user types were identified by Melucelli et al. (2001), "passive users" and "active users." Passive users make use of traditional transit (i.e., boarding and alighting at compulsory stops). No reservation is necessary since vehicles are guaranteed to serve each compulsory stop within a given time window. Active users ask for a ride while boarding or alighting at an optional stop. Active users must issue a service request and specify pick-up and drop-off stops as well as earliest departure and latest arrival times. In this study, transit vehicles have to be rerouted and scheduled to satisfy as many requests as possible, complying with passage-time constraints at compulsory stops, while between two compulsory stops optional stops can be activated on demand. The method used in this study integrates mathematical programming tools into a search framework, taking advantage of the particular structure of the problem formulation.

Dial-a-ride problems customarily use classical vehicle routing heuristics as described in Laporte (1992), Shen et al. (1995), Savelsbergh and Sol (1995), and Cordeau et al. (2000). These methods are rooted in arc and node manipulation, which generally is based on insertion, deletion, and exchange of stops in and out of a current tour. The computation of an upper bound in finding the optimal diala-ride solution is not a trivial issue. The linear relaxation of any arc-based integer linear programming model provides, to some extent, a loose bound. Therefore, heuristics are necessary to cope with practical routing problems.

The findings of the demand study presented in this article are used to construct simulation models for the development of routing strategies and generation of optimal solutions to the smart shuttle services problem. A few studies make use of simulation as a tool to devise satisfactory routing and scheduling solutions. Two types of simulation studies can be traced in the literature. The first type is the research conducted by Wilson et al. $(1970,1971)$ for evaluating various heuristic routing rules and algorithms used in a computer-aided routing system. These studies were developed for mainframe computers and have limitations in handling large-size road networks with different routing strategies. The second research type, by Fu (2001) and his team, considered the use of advanced technologies. Their studies use a simulation model, Sim-Paratransit, which was developed to evaluate advanced paratransit systems with AVL (automatic vehicle location) 
and CAD (computer-aided dispatch) systems. The ability to track continuously a transit vehicle's location enables the use of intelligent paratransit systems that contribute to the operation of the paratransit systems at a significantly improved level of productivity and reliability (Fu 2001).

Other advanced technologies include Advanced Traveler Information Systems (ATIS). ATIS is aimed at providing timely and accurate traveler information and bus or shuttle arrival. Although nearly a decade of ATIS research has been undertaken, very few projects have investigated the potential application of ATIS to fixed-route transit services. In the past, most federally-sponsored ATIS Field Operational Tests or Model Deployment Initiatives were directed at assisting drivers in ways of changing their travel behavior with advanced traveler information. The potential application of ATIS technologies to the bus transit service is significant, yet ATIS research in the transit area has lagged behind driver-oriented ATIS studies. Many transportation policy-makers and practitioners believe that transit users can benefit from getting real-time bus or shuttle information. The present study uses ATIS technologies for the Internet dispatch of up-to-the-minute smart shuttle arrival time so that end-users can readily retrieve shuttle information via the Internet. Synchronized BART and shuttle arrival times will also be posted via variable message signs at BART stations and other selected locations along shuttle routes. Low-tech technologies also will be used. Cellular phones will be used for the flexible-route flexible-schedule strategies. A customer will call the driver with his or her location, then the driver deviates from the standard route schedule and picks up the customer.

One of the reasons that people are reluctant to take transit is the uncertainty associated with bus arrival times. ATIS can disseminate real-time bus schedule information to those who are regular transit users as well as to the occasional transit rider. ATIS bus schedules also can attract those who have seldom or never used transit. When the risk of taking transit is reduced to an acceptable level, people will shift from driving to riding bus transit. Moreover, reasonably accurate arrival times or travel times would increase the confidence level of bus transit operators.

Like fixed-transit service, demand responsive transit service suffers from low ridership and high operating costs. As was evidenced in most demonstration projects, demand responsive transit service was not cost-effective, with two factors contributing to this. From the operator perspective, either the design concept had flaws or appropriate computer technologies were not available to efficiently operate the system. From the user perspective, operators did not consider the needs of 
the users. Most of these systems provided the services without asking what type of demand responsive service would attract consumers. While recognizing the importance of operating system efficiency, advanced routing algorithms or computing technologies may not necessarily generate increased ridership.

Previous field tests of demand responsive transit services showed their inability to draw enough consumers to support the system even with public subsidies. Dial-aride in the Boston area, a service that was later tested in other urban regions, had similar problems of low ridership and high operating cost (Multisystems 1977; Dave Systems 1977; Huron River Group, Missouri Transportation Associates, Bishop Engineers 1977; Maine Department of Transportation 1986; TransVision Consultants 1993). The reason was simply that the system was not attractive to consumers. For consumers to be attracted to the new dial-a-ride service, it had to be better than what they were using (i.e., light rail, bus transit, personal vehicle) (Urban and Hauser 1993). Yet there is little understanding of consumer behavior regarding what will make people favor demand responsive transit over other modes of transportation.

With the advance of computer and communications technologies, it is now possible to improve the demand responsive transit system with up-to-the-minute bus/shuttle arrival time and seamless operations between a short-haul feeder and long-haul express systems.

\section{Methodology}

Studies on why people do or do not use transit are numerous. Some people may have no option but to take transit (captured riders without a car), and others may take transit because the cost of parking is prohibitive or taking transit is more convenient than driving. We know a great deal about who the BART customers are and who the AC Transit customers are and why they use these services; however, we do not know why people would use smart shuttles. Since smart shuttles currently do not exist in the Castro Valley community, our objective is to discover consumer reaction to this new proposed service.

To obtain the needed consumer information, the study used the survey research method. The test market was identified as being within a 2-mile radius of the Castro Valley BART station. Four hundred telephone interviews were completed in this market area using a random-digit-dial sample based on the 1990 census tract information. (The 2000 census tract information was not available at the time of 
this market research.) During the last two weeks of September 2001, telephone interviews were conducted using the Computer Aided Telephone Interview (CATI) technique. The criteria used for screening survey participants were that the potential participants had to:

- be 18 years old or older,

- be a permanent resident of the house called,

- say BART was a possible means of transportation for them, and

- commute or make their most frequent trip away from home by some means other than walking or bicycling.

The margin of error for a 400 -respondent sample is +5.0 percent at the 95 percent level of confidence.

The survey questions included the following topics:

- trip characteristics,

- mode of access transportation to BART,

- willingness to use a smart shuttle,

- willingness to pay for the service,

- desired attributes in the shuttle service, and

- demographic characteristics of survey respondents.

The study identified features that would attract consumers in terms of the routing characteristics (i.e., intermediate stop options, express service), travel time, waiting time, number of stops, and willingness to pay for the shuttle service.

\section{Survey Results}

The results of the survey are presented in several parts. These include (1) demographic characteristics, (2) willingness to use the smart shuttle service, (3) willingness to pay for the service, and (4) attributes that would enhance the shuttle service.

Demographically, the sample was predominantly white, highly educated, and financially well off. The sample is a representation of those who live in the suburbs of the San Francisco Bay Area. This part of Alameda County is among the middle- and upper-middle income communities in the Bay Area and commuters typically drive to well-paying professional or highly-specialized jobs in Oakland or San Francisco. 
Most people have the flexibility to choose a transportation mode to get to work, school, or other destinations. However, some people are constrained by their jobs, schools, or other reasons, making it infeasible to consider certain travel modes. Survey participants were asked whether they had transportation options using public transportation. When the respondent did not have the option of taking BART, the survey was terminated. Surveying those with an option to take BART was important because the research interest was to assess the market for a shuttle service.

Of the participants, 64 percent commuted to work, 7 percent to school, and 2 percent both equally. More than 57 percent of the participants have flexibility in the time they start work. More than 80 percent start their work before 9 A.M. while less than 20 percent start work after 10 A.M. Among commuters, nearly four fifths (78\%) of the respondents drove to work alone while only 8 percent carpooled and 19 percent took public transit. Ten percent of the public transit users were those who parked their cars and rode BART.

Travel characteristics of commuters were significantly different from noncommuters $(p<.05)$. Among noncommuters, more people tended to drive alone than commuters (85\%), and few people carpooled (8\%), took public transit (5\%), and used the park-and-ride facility (2\%). Two thirds (37\%) of the noncommute trips were made for shopping, 10 percent were for driving children, 10 percent were for attending medical or dental appointments, and 18 percent were for social or recreational events. The remaining 19 percent were for personal business.

Most (72\%) of those who commuted with BART drove to the BART station by personal vehicle. Only 3 percent carpooled and 17 percent walked to the BART station. The median commute time by BART was 38 minutes, and the median travel time to get to the BART station was 10 minutes. The mean cost of public transit per day was \$4.50; per week, \$31.23; and per month, \$71.82.

More than 80 percent of respondents said that parking was free for them; 13 percent said they personally pay for parking; 5 percent reported that their company pays for parking; and 2 percent noted both they and their company pay their parking. However, there was no strong association between the parking situation and the mode of transportation, at least in this survey. The survey also showed that the cost of parking was relatively lower than the parking price in the central part of San Francisco or Oakland. The mean parking cost per day was \$8.11; per week, \$32.50; and per month, \$133.16. 
One of the critical problems for BART operation is access to BART. Recently, some residents of Castro Valley have said that they would consider using BART for their commute to work or school but the parking lot at the station always seems full, and it is difficult to find any other suitable parking near enough to the station. The question was how many people do not take BART because of the parking situation. Of those commuters who do not use BART, 16 percent said that they do not take BART because of the parking situation; 84 percent said they do not take BART for some other reason.

\section{Demand for a Shuttle Service}

After a brief description of a BART shuttle service was read to participants, they were asked to respond to the question how interested were they in using the shuttle service. Afterwards, they were asked about the cost of the service wait times, van size options, number of stops for pick-ups and drop-offs-all of which are important attributes for designing a shuttle. Participants were then asked how likely was it that they would use the service, given that the cost of the shuttle, wait time, trip time, and scheduling were acceptable.

\section{Interested in Using a Shuttle}

The survey asked the following question about a neighborhood shuttle service to provide easy access to BART: "Suppose a shuttle service were available that provided round-trip transportation to the closest BART station from a pick-up location near your home. The service would use comfortable, air-conditioned vans, and pick-ups would be scheduled for convenient times throughout the day and would be coordinated with BART train schedules. How interested would you be in this type of shuttle service, without considering the cost?" Using a 1-to-5 scale where "1" meant "not at all interested" and " 5 " meant "very interested," one quarter of the respondents said that they are very interested in using the shuttle service and one third said they are not at all interested in using the service. Approximately half of the respondents stated that they are interested in using the shuttle service to the BART station (Table 1).

Among the reasons for no interest in using the shuttle were:

- The BART station is close enough to walk (24\%)

- Need a car for work and errands (25\%)

- BART is not convenient (38\%) 


\section{Table 1. Interested in Using a Shuttle}

\begin{tabular}{llrr}
\hline Scale & Response Category & Percent & $\begin{array}{r}\text { Combined } \\
\text { Percent }\end{array}$ \\
\hline 5 & Very interested & 24.9 & \\
4 & Somewhat interested & 12.3 & 53.1 \\
3 & May be interested & 15.9 & \\
2 & Somewhat uninterested & 13.9 & 46.9 \\
1 & Not at all interested & 33.0 & \\
\hline
\end{tabular}

Interestingly, more than 70 percent of the BART users travel at least 1 mile to get to a BART station, while only 27 percent live within a six-block radius of a BART station. There was no association between the distance from the BART station and driving to the BART station. People living three or four blocks from the BART station drove to the station. People living miles from the BART station mostly drove to the BART station. Very few took public transit or carpooled.

Approximately 40 percent of the participants expressed a high likelihood of using the shuttle service. They also said they would be more likely to use BART if a shuttle service were available. When asked how many days a week participants thought they would use BART because of the shuttle service, they responded that they would use BART eight or more times a month.

\section{Attributes}

Several attributes were investigated with respect to the design of the shuttle service. Among them were the number of pick-ups and drop-offs, the size of a shuttle vehicle, acceptable number of riders, travel time, and wait time.

Important Attributes for Shuttle Design. For designing a shuttle service, we asked respondents to name the three most important attributes in order of priority. Participants said that the most important attribute was the cost of the shuttle service (mean 2.29). The second most important was overall travel time, including the waiting time for the shuttle either at BART or the pick-up location (mean 2.29). The third most important was the on-time reliability of the service at the pick-up location or at the BART station (mean 1.61).

Pick-ups and Drop-offs. When asked the maximum number of pick-ups that should be allowed per trip to the BART station, most people expected four to five 
pick-ups (median five pick-ups) on the way to the BART station. Similarly, they expected four to five drop-offs on the way home (median five drop-offs).

Maximum Number of Riders in a Van. When asked the maximum number of people each van should hold, respondents said that approximately 10 riders (median) on each trip would be desirable.

Travel Time. When asked if the average travel time to the BART station were slower than it currently is, would they still use the BART shuttle service? nearly one third (29\%) said they would take the shuttle, while half (53\%) said they would take the shuttle if it takes about the same time. Only 12 percent said they would take it if it were faster. When asked if the average travel time to the BART station were 20 minutes longer than it takes currently to get to the BART station, would they use the shuttle to the BART station? one fifth (20\%) responded that they would use it if it took 20 minutes longer, 20 percent said they would if 15 minutes longer, 40 percent said they would if 10 minutes longer, 20 percent responded they would if 5 minutes longer. The survey suggests that people are willing to accept a longer travel time using a shuttle for whatever the benefits they perceive.

Arrival Time and Schedule Information. One of the reasons that people are hesitant to take transit is the uncertainty associated with bus arrival times. ATIS can disseminate real-time bus schedule information to those who are regular transit users as well as to the occasional transit rider. ATIS bus schedules also can attract those who seldom or never used transit in the past. When the risk of taking transit is reduced to an acceptable level, people will shift travel mode from driving to bus transit. Reasonably accurate arrival times or travel times would increase the confidence level of bus transit operators. A strong relationship between transit agencies and ATIS could help Metropolitan Planning Organizations (MPOs) to improve the overall Bay Area transportation system. The MPO's largest concern is how to change mode choice decisions from SOVS to high-occupancy vehicles (HOVs).

Cost. The cost question for riding a shuttle was constructed to ask about the highest price first and then subsequently lower prices. For the question: "Suppose the cost for the shuttle service were $\$ 1$ per one-way trip, how likely would you be to use this service? Would you say that you definitely would use the service, probably would use this service, might or might not use the service, probably would not use the service, or definitely would not use the service?" Responses showed that approximately two thirds (61\%) of the respondents would be interested in taking a shuttle at the price of $\$ 2$ for a one-way trip, and half said they would be interested if the cost were $\$ 1$. 
As expected, consumer interest in using the shuttle service is highly elastic with respect to the cost of the shuttle service (Table 2, Figure 1). However, it is found that the price elasticity is not directly proportional to the cost of the shuttle service. Willingness to use the service is significantly different between the low and the high cost of the shuttle service $(p<.05)$.

Frequency of Using the Shuttle Service. When asked how often they would be willing to use the shuttle service if the cost were acceptable, most respondents said that they would use the service two to three times a week (mean 2.57, median 2).

Table 2. Willingness to Pay for the Shuttle Service

\begin{tabular}{llrrrrrr}
\hline Scale & Response & $\mathbf{\$ 5}$ & $\mathbf{\$ 4}$ & $\mathbf{\$ 3}$ & $\mathbf{\$ 2}$ & $\mathbf{\$ 1}$ & $\mathbf{5 0 c}$ \\
\hline & & $(\%)$ & $(\%)$ & $(\%)$ & $(\%)$ & $(\%)$ & $(\%)$ \\
5 & Definitely would & 4.4 & 1.8 & 3.5 & 8.1 & 14.8 & 7.0 \\
4 & Probably would & 12.5 & 10.6 & 21.6 & 32.9 & 36.4 & 27.9 \\
3 & Might/might not & 19.4 & 18.6 & 24.6 & 30.9 & 33.0 & 41.9 \\
2 & Probably would not & 32.6 & 39.4 & 28.1 & 16.1 & 11.4 & 14.0 \\
1 & Definitely would not & 31.1 & 29.6 & 22.5 & 12.1 & 4.5 & 9.3 \\
\hline & Statistical significance & & $\mathrm{p}<.05$ & $\mathrm{p}<.05$ & $\mathrm{p}<.05$ & $\mathrm{p}<.05$ & $\mathrm{p}<.05$
\end{tabular}

Figure 1. Willingness to Pay for the Shuttle Service

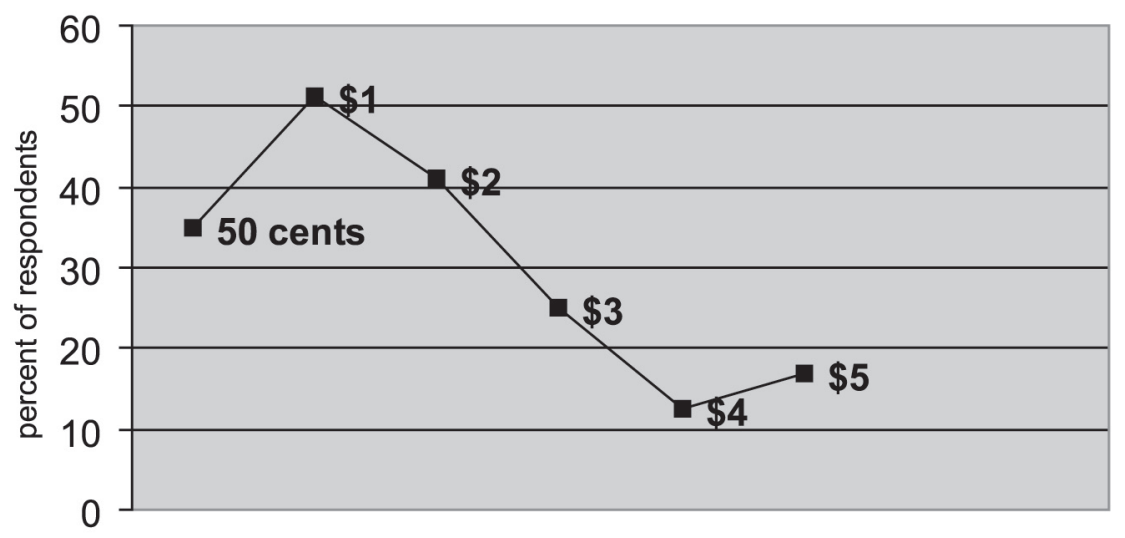


Wait Time. Questions about wait time were posed at the same time as the cost of the shuttle service. It was asked if the waiting time is 20 minutes, 15 minutes, 10 minutes, and 5 minutes, how likely would the participants be to use the shuttle service? The answers were precoded in five scale responses: "definitely would," "probably would," "might/might not," "probably would not," and "definitely would not." The survey showed that the longer the wait time, the less willing people are to take the shuttle, but there was not a significant difference between a 10-and a 5-minute wait time (Table 3, Figure 2). This suggests that half of the shuttle users are willing to accept a 5- to 10-minute wait time.

Payment Method. Participants were asked "How would you prefer to pay for the service if you were to use the shuttle service?" More than 55.4 percent were inter-

Table 3. Willingness to Wait for the Shuttle Service

\begin{tabular}{llrrrr}
\hline Scale & Precoded Response Category & $\mathbf{2 0} \mathbf{~}$ in & $\mathbf{1 5} \mathbf{~}$ in & $\mathbf{1 0} \mathbf{~}$ in & $\mathbf{5 ~} \mathbf{~ m i n}$ \\
\hline & & $(\%)$ & $(\%)$ & $(\%)$ & $(\%)$ \\
5 & Definitely would & 8.9 & 3.4 & 11.2 & 10.0 \\
4 & Probably would & 26.8 & 25.7 & 40.8 & 41.7 \\
3 & Might/might not & 21.5 & 25.2 & 28.0 & 35.0 \\
2 & Probably would not & 21.6 & 24.0 & 10.4 & 6.7 \\
1 & Definitely would not & 21.2 & 21.7 & 9.6 & 6.7 \\
\hline
\end{tabular}

Figure 2. Willingness to Wait for a Shuttle Ride

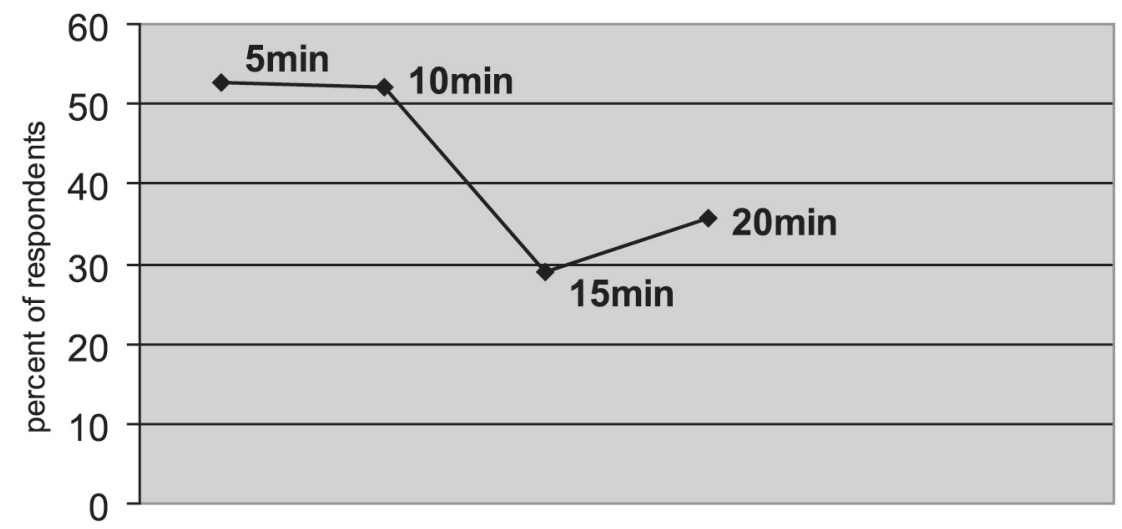


ested in paying for the service on a per-user basis. Only 11.2 percent responded in favor of the weekly-fee basis and 31.2 percent said they would work with a monthly subscription arrangement.

Preferred Means of Receiving Information about the Shuttle. When asked about how they would prefer to receive information about the shuttle service, including the shuttle schedule, cancellation, and new services, 62 percent of the respondents said that they would like to receive the information from a pamphlet. Approximately one third (30.9\%) would like to receive it through the Internet, and only 5.9 percent would like to retrieve it by telephone.

Providing transit information through the Internet is more cost-effective than over the telephone because Internet technology is widely deployed and does not require human operators. Automation for telephone information still requires technical improvement. The survey showed that nearly three quarters $(73 \%)$ of the participants had Internet access at home and 54 percent at work. While only 58 percent had personal cellular phones, 81 percent had a personal computer at home, and 59 percent had one at work.

Benefits of the Shuttle. Because the question "What would be the biggest benefits personally of using the shuttle service?" was an open-ended question and accepted up to three responses, the percentages shown in this section are not mutually exclusive. A variety of personal benefits of the shuttle service were mentioned. Among the personal benefits were:

- convenience, including no need to park (25\%), avoid walking in bad weather $(2 \%)$, avoid wear on vehicle (21\%), and others (30\%),

- safety, including reduced stress and anxiety ( $8 \%$ ), less chance of an accident (2\%), avoidance of traffic fights (18\%),

- travel time savings (14\%),

- less cost (18\%),

- reduced pollution (7\%), and

- chance to meet people and socialize (2\%).

The survey suggested that most people perceive benefits from the shuttle service. It would be convenient for them and could save travel cost and time and increase safety and reduce stress. 
Respondents also mentioned that there would be a great deal of social benefit to be gained from the shuttle service. Among the societal benefits were:

- reduction of traffic congestion (52\%),

- reduction of air pollution (40\%),

- easier to get around, greater mobility, greater accessibility (29\%),

- less crowded parking lots at the long-haul express transit station (10\%),

- saving of money and lower taxes (7\%), and

- reduction in accidents (8\%).

\section{The Likelihood of Using the Shuttle Service}

After a series of questions about design attributes were posed, including the acceptable fare, wait time, the number of pick-ups and drop-offs, and the size of a shuttle vehicle, participants were asked again: "If the shuttle service cost what you are willing to pay and has acceptable wait times, trip length, and scheduling times how likely do you think you would be to use the shuttle service to get to and from the BART station?" Using the 5-point scale where "1" meant "not at all likely" and " 5 " meant "very likely," 57.2 percent said they would be likely to use the shuttle service and 29.2 percent said they may use it. Only 13.7 percent said they were not likely to use the service. This response is significantly different $(P<.05)$ from the earlier question concerning how interested respondents were in using the shuttle service without considering the cost. The latter responses, after learning about the shuttle attributes, were far more receptive to the shuttle service than the former responses (Table 4). In the latter case, nearly 60 percent of the respondents said that they would be likely to use the shuttle, while in the former case the same sample indicated that less than 40 percent would be interested in using the shuttle.

In response to the interest in using the shuttle, there was no difference between commuters and noncommuters. Similarly, there was no difference between commuters and noncommuters in their likelihood of using the shuttle after learning more about its design.

When asked whether they think they would be more likely to use BART because of the shuttle service or whether it would make no difference in how frequently they use BART, 43.3 percent of those surveyed said that they would be more likely to use BART if a shuttle is provided, 23.3 percent said much more likely, 17 percent 
Table 4. Comparative Response $(\mathrm{P}<.05)$

\begin{tabular}{llcc}
\hline Scale & $\begin{array}{c}\text { Precoded response } \\
\text { category }\end{array}$ & $\begin{array}{c}\text { How would you be } \\
\text { interested in using } \\
\text { the shuttle? }\end{array}$ & $\begin{array}{c}\text { How likely would you } \\
\text { use the shuttle? }\end{array}$ \\
\hline & & $(\%)$ & $(\%)$ \\
5 & Very interested & 24.9 & $30.3 \%$ \\
4 & Somewhat interested & 12.3 & 26.9 \\
3 & May be interested & 15.9 & 29.2 \\
2 & Somewhat uninterested & 13.9 & 12.2 \\
1 & Not at all interested & 330 & 1.4 \\
\hline
\end{tabular}

said somewhat more likely, and 56.8 percent said that the shuttle would not necessarily cause them to take BART more often.

The analysis showed that public interest in taking a shuttle service was closely associated with gender, automobile ownership, ethnicity, and employment status. Females were more interested in taking a shuttle than males $(P<.05)$. Employed people were more likely to use BART because of the shuttle service $(P<.05)$. Households without a car or with fewer cars were more interested in taking a shuttle ( $P$ $<.05)$. People among the Asian-American, Hispanic, Native American, and mixed race groups were marginally more interested in taking transit than the white or black race ( $\mathrm{p}=.058)$. However, further analyses showed that the likelihood of taking a shuttle was not closely associated with gender, automobile ownership, ethnicity, and employment status. There was no difference between commuters and noncommuters in their interest or the likelihood of taking a shuttle for the BART service. Nonetheless, the study found that availability of parking at their workplace was closely associated with taking BART $(P<0.05)$.

\section{Smart Feeder/Shuttle Design: Routing Strageties}

Once the major elements of the smart feeder/shuttle transit service are defined, attention should be given to smart routing strategies. These strategies represent the flexibility and, to some extent, part of the attractiveness of the transit system. Ten routing strategies were investigated in this work:

1. fixed route with a fixed schedule (timetable) and fixed direction;

2. fixed route with a flexible (demand-driven) schedule, fixed direction; 
3. fixed route with a flexible schedule, bidirectional;

4. fixed route, flexible schedule, fixed direction, with a possible short-turn;

5. fixed route, flexible schedule, bidirectional, with a possible short-turn;

6. fixed route, flexible schedule, fixed direction, with a possible shortcut;

7. fixed route, flexible schedule, bidirectional, with a possible shortcut;

8. fixed route, flexible schedule, fixed direction, with possible short-turn and shortcut;

9. fixed route, flexible schedule, bidirectional, with possible short-turn and shortcut; and

10. flexible (demand responsive) route with a flexible schedule.

Fixed direction means that the shuttle will always maintain the same direction of travel (same sequence of stops), whereas bidirectional allows for having the flexibility to select the direction based on real-time demand information. The term "shortcut" means that, based on certain loading threshold and synchronization criteria, the shuttle will not continue its fixed route and, instead, will use the shortest path (minimum travel time) to arrive at the train station. The loading threshold is a given (input) number of passengers on board the shuttle. The synchronization criterion means matching the shuttle's new (shortcut) arrival time with an earlier train than that originally planned if the entire route is completed. The term "shortturn" means that based on certain loading threshold and synchronization criteria, the shuttle will not continue on its fixed route. Instead, it will turn around and arrive at the train station in the opposite direction, with the possibility of picking up passengers who were too late to be picked up when the shuttle passed through the station previously. The loading threshold and synchronization criteria for the short-turn strategy (including the consideration of more pick-ups) are the same as for the shortcut strategy. Each strategy allows the flexibility of the other; that is, the loading threshold of the shortcut strategy is higher than the loading threshold of the short-turn strategy. If the latter is reached and there is the possibility of picking up $x$ passengers (after turning around), where $x$ is equal to or greater than the difference between the two loading thresholds, then the short-turn strategy is recommended.

Figure 3 depicts the 10 strategies on a small network with two shuttle routes, one with a dashed line and one with a dotted line. The clock on the upper-right-hand side exhibits the fixed schedule (in only one strategy); when crossed with $x$, it means a flexible schedule situation. Arrows in both directions of the route means 
Figure 3. Routing Strategies Considered on a Small Network Example

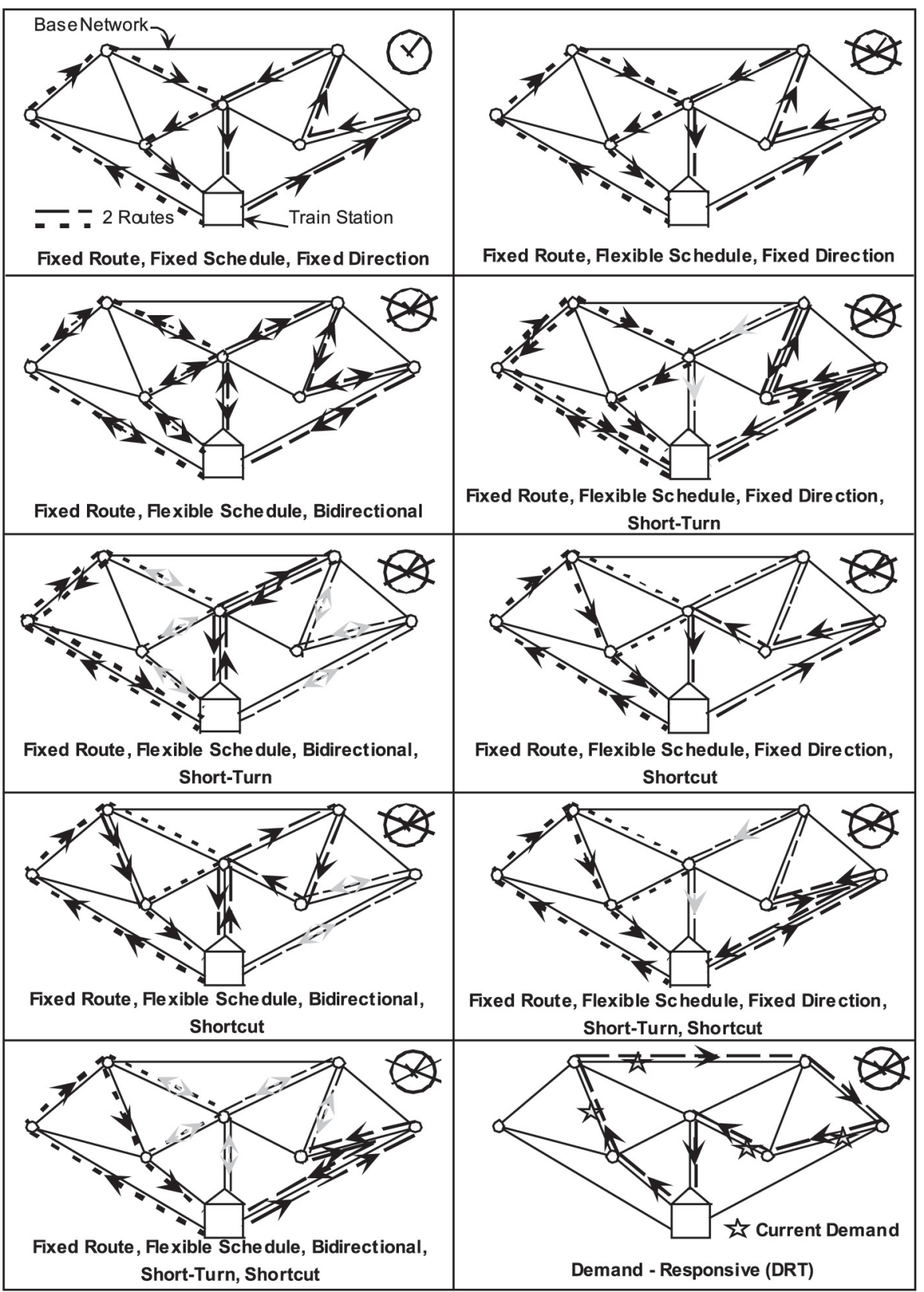


a bidirectional situation. It can be seen in Figure 3 that the lines with the arrows deviate from the fixed route in the shortcut strategy. The arrows turn around at a certain point of the network in the short-turn strategy, while both representations appear in the strategy involving a possible combination of shortcut and short-turn runs,. The last strategy is for a DRT-type of service, allowing for the creation of a new route every time, based on the trip bookings.

The idea of covering almost all possible practical routing strategies stemmed from the need to arrive at user desires and understandings. Certainly, there is no intention that all strategies be used at the same time; rather, the idea was to examine which strategy was best for a given demand pattern and magnitude while taking into consideration the real-time traffic situation in the area of the shuttle's trips. A simulation model was devised for that purpose. This simulation tool, explained in Ceder and Yim (2002), enables a comparison of the various strategies, based on the following measures:

- sum of total time (in passenger-hours) from passenger pick-up to traindeparture times,

- sum of total time (in passenger-hours) riding the shuttle vehicle,

- sum of total waiting time (in passenger-hours) for the train,

- sum of total waiting time (in passenger-hours) for the shuttle vehicle, and

- total number of transit vehicles (by number of seats) required to meet the demand.

These measures of travel and waiting times and number of vehicles characterize the effectiveness and efficiency of each strategy. Certainly, the strategy selected for a given demand is the one with the minimum weighted travel and waiting times (user perspective) and the minimum number of vehicles (operator perspective). These routing strategies underwent a simulation process explained and interpreted in Ceder and Yim (2002).

Once the analysis of the feeder/shuttle service is completed, we recommend the next step should be a pilot study, the implementation of which can follow, for example, the 12 steps shown in Figure 4. These 12 steps of Figure 4 can serve as a framework for a master plan of a pilot where each outcome of a previous step becomes an additional input to the next step except for step 6 .

The pilot master plan starts with a demand analysis by time of day and day of week to find the origin-destination pattern and consumer oriented features. The second 


\section{Figure 4. Overview of Feeder/Shuttle Pilot Master Plan}

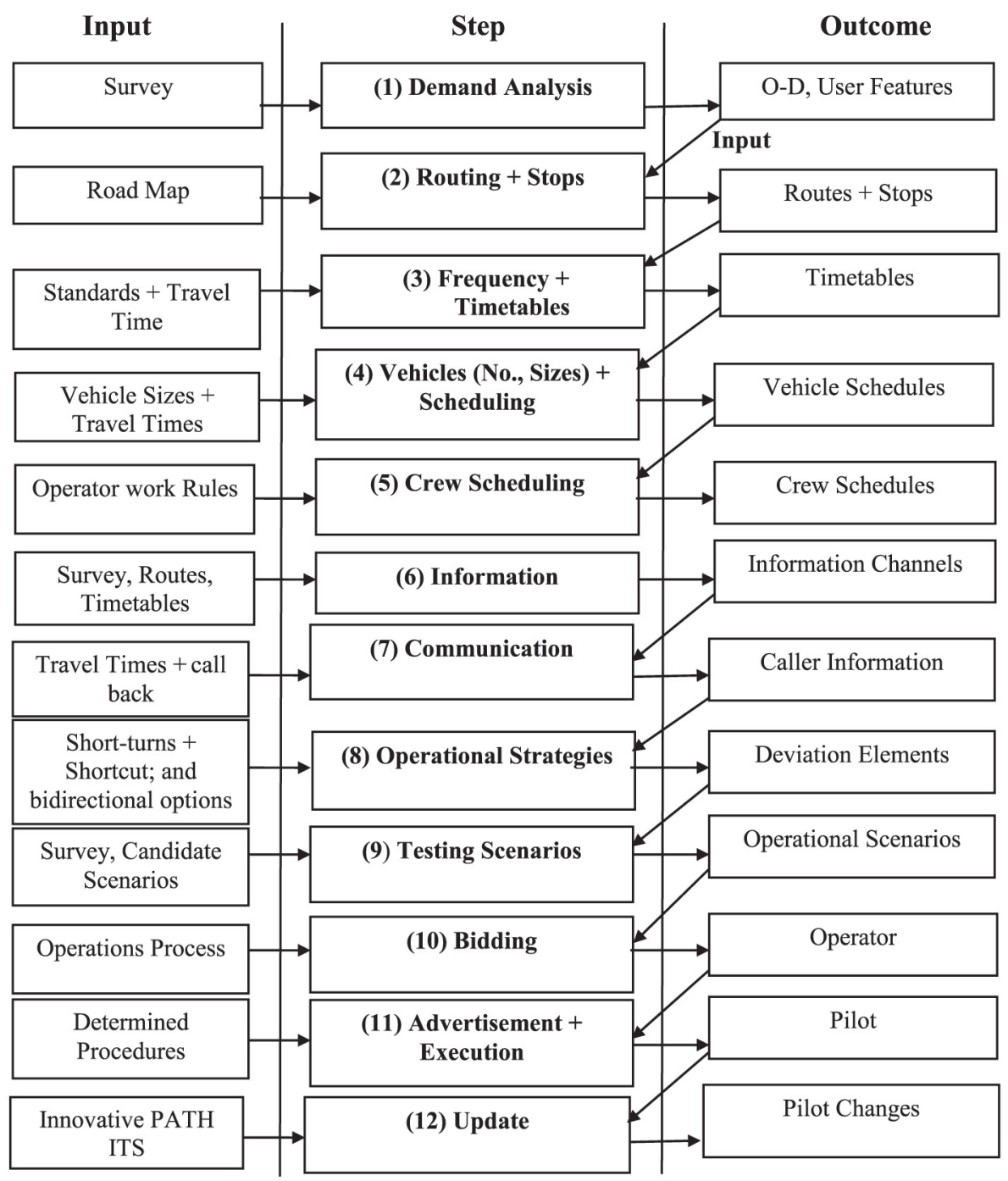

step is to design the fixed routing and stop system and the third-to determine the base frequencies and timetables for each route. The fourth step is to determine the number and size of the feeder/shuttle vehicles and to create the chains of trips (vehicle schedules) which will serve the fifth step of constructing the crew schedules. 
The pilot plan continues in step 6 with the establishment of effective information channels and instruments (e.g., telephone center, internet, newspapers, radio, TV, mail leaflets) which will lead to the development of a user-friendly communication procedures between the users and the operator in the next step. Step 8 constructs the DRT operational strategies without the use of the fixed routing/stop/schedule system. Step 9 determines the testing scenarios of the pilot while step 10 presents the process to select an adequate operator. Step 11 uses proper advertisement tools to approach an operable pilot, and, finally, the last step of the plan aims at improving the instruments, procedures and strategies with the use of innovative ITS (Intelligent Transportation Systems) elements.

\section{Conclusions}

This article documented the survey results of Castro Valley, a suburban community in the San Francisco Bay Area of California that is experiencing rapid growth of housing developments along with the elderly and the young. There was evidence in the survey of demand for a smart shuttle service, as approximately half of the commuters with the option to take BART would be likely to use such a smart shuttle service. There was no strong association between age or income group and the likeliness of using the shuttle service. However, interest in using the service is closely associated with gender, auto ownership, and ethnicity and employment status.

The study suggests that there is a strong potential for the deployment of a smart shuttle service in Castro Valley. The present study fills the gap in our understanding of a potential market for a short-haul feeder system to support the long-haul express transit. The Castro Valley study is our first field test in the San Francisco Bay Area. The field test of the smart shuttle project is expected to be deployed in the near future following interest among some of the Bay Area cities. The value of the innovative transit service is in evaluation. The evaluation of the field test will provide valuable insights into the technical validity of the smart shuttle and the cost-effectiveness of the system.

In addition, this work attempts to construct a new idea for designing an integrated smart feeder/shuttle bus service. Ideally, this smart bus system will provide advanced and attractive feeder and distributor services that operate reliably and relatively rapidly, and are part of the passenger door-to-door chain with smooth and synchronized transfers. Ten different routing strategies are proposed with 
all the combinations of fixed/flexible routes, fixed/flexible schedules, one or bidirectional concepts, and shortcut (shortest path) and/or short-turn (turn around) concepts. Finally a 12-step implementation framework is shown to bridge between the consumer research results and realization of the smart feeder/shuttle bus design.

\section{Acknowledgments}

This is to acknowledge with deep grief that, after the completion of this paper, the first author, Dr. Y. B. Yim, passed away. Her death was a shock and loss to all who knew her personally and professionally. This paper is yet another remembrance of Dr. Yim's many achievements and contributions to the transportation community.

\section{References}

Borndorfer, R., M. Grotschel, F. Klostemeier., and C. Kuttner. 1999. Telebus Berlin: Vehicle scheduling in a dial-a-ride system. In N.H.W. Wilson, ed., ComputerAided Transit scheduling, lectures notes in economics and mathematical systems 471. Berlin: Springer, 391-422.

Ceder, A., Y.B. Yim. 2002. Integrated Smart Feeder/Shuttle Bus Service, UCB PATH Program publication.

Comsis Corporation (1988). Cost analysis methodology for demand responsive service, Urban Mass Transit Administration and the Maryland Department of Transportation.

Cordeau, J.-F., G. Laporte, and A. Mercier. 2000. A unified tabu search heuristic for vehicle routing problems with time windows. Technical Report CRT-2000-03. Montreal: Centre de Recherche sur les Transports, University of Montreal.

Dave Systems, Inc.1977. An integrated public transportation system for the cities of Fremont, Newark, and Union City, the Tri-City Transit Implementation Project.

Fu, L. 2001. Simulation model for evaluating intelligent paratransit systems. Transportation Research Record 1760. Washington, DC: TRB National Research Council, 93-99. 
Huron River Group, Missouri Transportation Associates, Bishop Engineers. 1977. Dial-a-ride study: Report No.1, Dial-a-ride service potential in the Kansas City Metropolitan Region.

loachim, I., J Derosiers, Y. Dumas, M. Solomon, and D. Villeneuve. 1995. A request clustering algorithm for door-to-door handicapped transportation. Transportation Science 29: 35-139.

Laporte, G. 1992. The travelling salesman problem: An overview of exact and approximate algorithms. European Journal of Operational Research 59: 231247.

Maine Department of Transportation. 1986. An analysis and action strategy for select surface passenger transportation services in Maine.

Melucelli, F., M. Nonato, T.G. Crainic, and F. Guertin. 2001. Adaptive memory programming for a class of demand responsive transit systems. In Stefan Voss and Joachim R. Danuna, eds., Computer-aided scheduling of public transport. Lectures notes in economics and mathematical systems 505. Berlin: Springer, 253-273.

Multisystems, Inc. 1977. State of Wisconsin Urban Mass Transit Demonstration Program: Merrill project, Final Report.

Savelsbergh, M.W.P., and M. Sol. 1995. The general pickup and delivery problem. Transportation Science: 17-29.

Shen, Y., J.-Y. Potvin, J.-M. Rousseau, and S. Roy. 1995. A computer assistant for vehicle dispatching with learning capabilities. Annals of Operations Research 61: 189-211.

TransVision Consultants Ltd. 1993. Evaluation of Handyline: Vancouver's automated paratransit information system. BC Transit.

Urban, G., and J. Hauser. 1993. Design and marketing of new products, 2nd ed. Englewood Cliffs, NJ: Prentice Hall.

Wilson, N.H.M., J.M. Sussman, B.T. Higonnet, and L.A. Goodman. 1970. Simulation of a computer-aided routing system (CARS). Highway Research Record 318. Washington, DC: HRB National Research Council, 66-76.

Wilson, N.H.M., J.M. Sussman, H. K. Wong, and B.T. Higonnet. 1971. Scheduling algorithms for a dial-a-ride system. Cambridge: Massachusetts Institute of Technology. 


\section{About the Authors}

Y. B. YıM obtained her B.Arch. (architecture/structural) at the University of Washington, M. Arch. (architecture/urban design) at the University of Washington, M.C.P. (city planning) at the Harvard University, and Ph.D. (Transportation Engineering) at the University of California at Berkeley. She was a member of: Intelligent Transportation Society of America ATIS Committee, Transportation Research Board Committee on User Information Systems, Western Regional Science Association, and Transportation Research Board. Dr. Yim has written articles and reports on numerous transportation-related topics, including traveler information and travel behavior, demand responsive transit systems, evacuation planning and emergency service, and consumer research in transit.

Avishal (Avi) Ceder (ceder@tx.technion.ac.il) obtained his B.Sc. (1971) at the Technion (industrial and management engineering), and M.Sc. (1972) and Ph.D. (1975) at the University of California at Berkeley (major in transportation with emphasis on operations research and human factors). Dr. Ceder has served in the Technion since 1975 and MIT-Boston as a Visiting Professor since 1981. He is a Principal Investigator at the Technion and is or was involved with teaching and research projects at the University of California at Berkeley, M.I.T, Hong Kong University of Science and Technology, Hong Kong Polytechnic University, University of Tokyo, University of Rome, and at the Graduate School of Business, Sydney University, focusing on public transport operations and service planning, operations research, intelligent transportation systems, traffic safety and control, and logistics.

Dr. Ceder has written more than 100 articles in refereed journals, book chapters, proceedings and has authored three books: Network Theory and Selected Topics in Dynamic Programming, System Analysis as an Introduction to Operations Research, and Public Transport: Operations and Service Planning (Lecture Notes). In addition, he served as chief scientist of the Israel Ministry of Transport, Israel delegate at the Transport Program of the European Community, president of the Israel Association of Transportation Research, and a member of various organizing committees of international symposia and workshops. 